\title{
Conciliación y Arbitraje en el Perú: presente y futuro
}

\section{Aníbal Quiroga León}

«[...] a un hombre se le cayeron tres monedas, y otro las encontró. Ambos fueron ante el juez y los dos insistían en que no les correspondía quedarse con el dinero. El que dejó caer las monedas, explicó que no merecía recuperarlas porque la pérdida se debía a su propia negligencia. El que las encontró argumentó que no podía quedarse con ellas, porque no le pertenecían originalmente.

Después de escuchar a las partes, el juez sacó otras tres monedas de su propio bolsillo y las agregó a las otras, luego dividió las seis entre los tres. Al final dijo: el que dejó caer las monedas, y que tenía tres al principio, ahora tiene dos; el que encontró tres monedas, también tiene dos; yo tenía tres monedas en mi bolsillo, pero ahora tengo dos. Cada uno de nosotros perdió una moneda. Este es mi Fallo».

Decisión judicial del periodo feudal Edo $(1600-868)^{1}$

\section{Introducción}

La Conciliación y el Arbitraje constituyen figuras judiciales fascinantes. Muchos se preguntarán cómo pueden ser definidas como judiciales si son muchas veces constituidas de modo pre-judicial o en sede privada arbitral, dado que la ideología imperante sobre la materia, y cierta desinformación, en los últimos tiempos han presentado a estas instituciones como diferentes, hasta antagónicas, cuando ello en realidad no es así.

Lo anterior se ve ahora más resaltado cuando se presenta, en la hora actual de crisis generalizada -en mayor o en menor grado- de la admi-

1 Tomado de Lorenzo Zolezzi. "Relevancia social del Juez Civil»; Ponencia ILANUD, San José, 1987. 
nistración de justicia globalizada, los ADR's (Alternatives Dispute Resolutions), que en una traducción semántica que equivoca su concepto jurídico, se presenta de modo grueso como «Formas alternativas de solución de conflictos". Y decimos equívoca, por cuanto -en realidadni la Conciliación ni el Arbitraje son, en puridad, formas ni medios alternativos al sistema judicial para la solución de los conflictos intersubjetivos de una sociedad, sino formas antecedentes de solución de esos conflictos como instrumentos que el Derecho procesal ofrece para la solución de tales conflictos de modo previo al proceso judicial jurisdiccional.

La Conciliación y el Arbitraje comparten la misma naturaleza jurídica del proceso judicial. Tienen la misma finalidad. Repiten en mayor o en menor grado el mismo método. Y se sirven del proceso para su realidad. Son, en realidad, procesos judiciales privados o arbitrales de forma variada frente a la única solución que el Estado ofrece a los conflictos intersubjetivos de sus ciudadanos y que puede definirse como proceso judicial jurisdiccional ${ }^{2}$.

En los orígenes de la humanidad, donde hunde sus raíces el proceso como medio pacífico de solución de controversias, las disputas al interior de una comunidad fueron inicialmente resueltas por mano propia. Regía entonces la ley del más fuerte, la ley de la selva, la autotutela en la defensa de los derechos de cada cual. Con el desarrollo y evolución de las condiciones sociales de vida, las gentes dejaron de pegarse y de matarse para dirimir la razón y los derechos, y empezaron a establecer acuerdos bilaterales de solución, a negociar, a hacer autocomposición, para la composición de los derechos de las partes. Finalmente, en el grado máximo del desarrollo social, frente a la limitación de la negociación cuando las partes no necesariamente llegaban a un acuerdo, o frente a la injusticia que se podía lograr porque siempre hay una parte más fuerte y una más débil, una más astuta y una más lerda, una más poderosa y otra menos pudiente, y ante el temor cierto de que el fracaso les hiciera involucionar nuevamente hacia la confrontación directa, con el grave perjuicio que ello supondría, decidieron hacer intervenir a un tercero, imparcial, que con la aceptación de los contendores y una necesaria legitimación social, determinase finalmente lo que a cada

2 Pedro Aragoneses Alonso. Proceso y Derecho Procesal; Ed. Aguilar; Madrid, 1960. 
cual correspondía. Descubrieron entonces la heterocomposición como trilogía judicial para la solución pacífica de sus controversias ${ }^{3}$. Ello se encuentra estupendamente condensado por González Pérez ${ }^{4}$, quien al efecto señala:

«Los hombres que en su estado primitivo natural no reconocían superior que los defendiesen de insultos, opresiones y violencias, estaban, por consiguiente, autorizados para hacerlo por sí propios; la experiencia les hizo entender los graves daños a que los conducían estos medios, pues no podía defenderse por sí mismos, o excediendo los justos límites para conservarse, excitaban turbaciones a que eran consiguientes mayores desavenencias, injurias y muertes; y consultando otros medios que mejorasen en la seguridad de sus personas sin los riesgos anteriormente indicados, acordaron unirse en sociedades y confiar su defensa y la de todos sus derechos a una persona que mirándolos con imparcialidad les distribuyese sus derechos y los conservase en paz y en justicia».

Y este tercero podía ser el anciano de la comunidad, el brujo, a quien se considerara el más sabio, el líder, el azar, el sacerdote, etc. ${ }^{5}$.

3 Niceto Alcalá-Zamora y Castillo. Proceso, Autocomposición y Autodefensa; Textos Universitarios; UNAM, México, 1970.

4 Jesús González Pérez. El Derecho a la TutrelaTutela Jurisdiccional; Ed. Civitas, Madrid, 1984; p. 19 y ss.

5 Es Calamandrei quien señala que históricamente la cualidad preminentepreeminente de la idea de juzgar, desde los albores de la civilidad ha sido la búsqueda de la ansiada imparcialidad. Así, de modo muy significativo, el juez se confunde con el sacerdote o brujo, que requiere de la ayuda de la inspiración de la superstición o magia, y hallará la motivación de sus fallos en el simple vuelo de las aves o en las vísceras palpitantes de las víctimas así inmoladas. El juicio de Dios, la prueba de fuego, el occulo chiuso, etc., serán expedientes suficientes para introducir en el juicio la garantía de la necesaria imparcialidad, entendida como una fuerza superior a todo cáculocálculo humano y a todo poder terrestre, como la indeferencia de los dioses y la suerte ciega. También el método seguido el famoso juez Bridoye di Ravelais, que metiametía en una balanza los escritos de los litigantes dando la razón a los que pesaran más, como la justicia del cadí turco que decidía a ojos cerrados lanzando puñales a los eventuales contrincantes, sacrificándose al que perdía el juicio. Cuenta tambientambién la experiencia de etnólogo extranjero que presenció en una tribu africana, habitante en las orillas de un lago: cuando se producía una disputa, los litigantes eran atados a dos palos erigidos en la proximidad del lago, a igual distancia 
Dentro de una de las fases del desarrollo del derecho en Roma se le denominó árbiter, para luego en la fase final adoptarse la de iudicum de la que se deriva el vocablo juez (el que dice la ley o el que dice el derecho), y la iurisdictio (jurisdicción) como la acción de decir el derecho (hoy la potestad jurisdiccional reservada de modo exclusivo y excluyente al Estado) ${ }^{6}$.

a) Autotutela

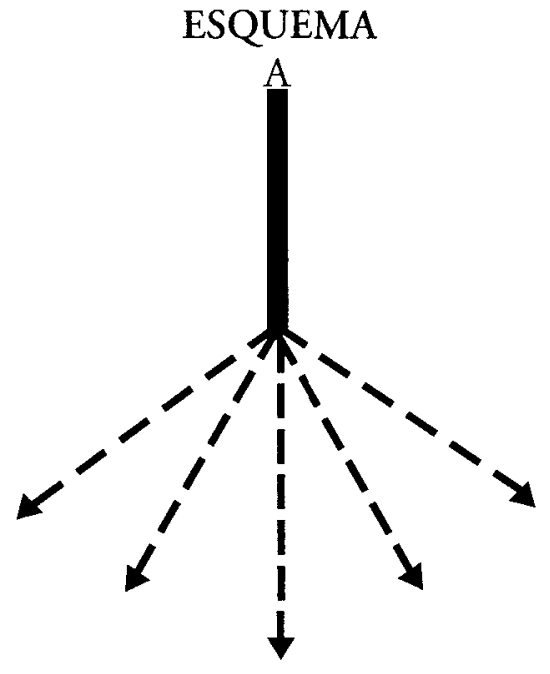

B) Autocomposición

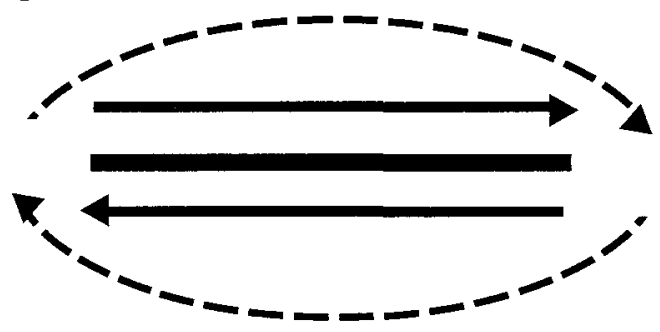

el uno del otro con respecto al agua, quedándose allí a la espera de la sentencia. Al cabo de un rato, el oleaje anunciaba la presencia del juez: un viejísimo cocodrilo, muy enterado en aquellos menesteres, que después de haber soperadosopesado muy seriamente la cuestión, se acercaba muy lentamente a uno de los palos. El litigante devorado había perdido la causa, con evidente condena accesoria de propia vida. Piero Calamandrei. Processo e Democrazia. CEDAM, Pádova, 1954; pp. 46-49; también ed. bajo el título Proceso y Democracia; EJEA, Bs. As., 1960; con la traducción de don Héctor Fix-Zamudio.

6 El Arbitraje constituye la cuna del proceso jurisdiccional. Los antiguos jueces 
c) Heterocomposición No procesalizada

d) Heterocomposición

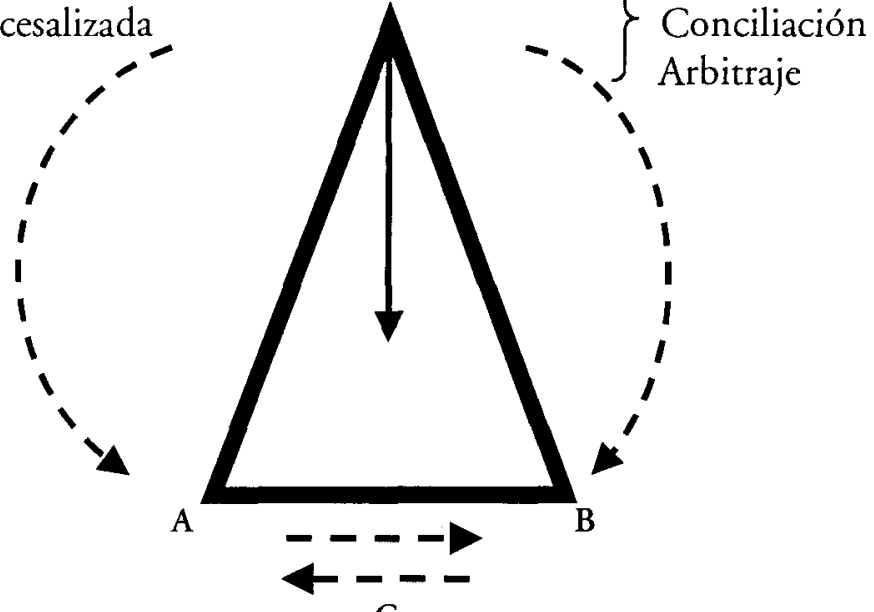
procesalizada

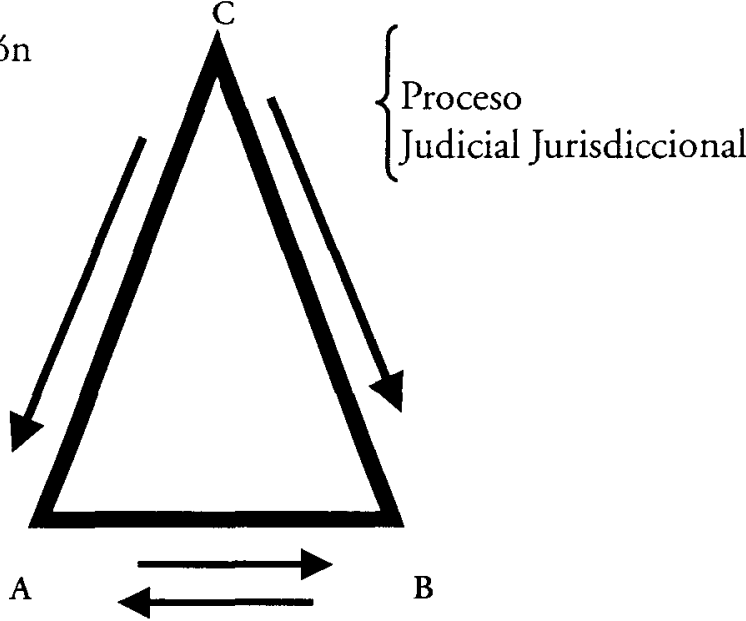

Como señala con agudeza Calamandrei ${ }^{7}$, la idea fundamental que se encuentra en los más remotos albores de la civilización, y que constituye el germen de todos los institutos judiciales posteriores, es la siguiente:

romanos, tanto dentro de la Ordinaria Cognitio como dentro de la Extraordinaria Cognitio recibieron la denominación de Pretores o Arbiter. Aníbal Quiroga León. "Naturaleza Jurídica del Proceso Arbitral. Nulidad de Juicio Arbitral: Excepción de Cosa Juzgada»; en El Jurista Revista Peruana de Derecho, No. 7/8; Lima, 1992.

7 Piero Calamandrei. Instituciones del Derecho Procesal; Bs. As., 1943; pp. 148 y ss.; cit. por Pedro Aragoneses Alonso. Op. cit.; p. 47 y ss. y cit. 76. 
"Para alcanzar una pacífica solución del conflicto, es necesario sustraerlo a las partes y confiar su decisión a un tercero extraño al conflicto, que por estar desinteresado pueda ser imparcial. Pero no se debe creer que este tercero imparcial, que se opone entre los sujetos del conflicto, sea originariamente el mismo Estado, con un órgano suyo con carácter de juez público. En un principio, el Estado se limita a favorecer y a disciplinar el uso del arbitraje, esto es, el uso de someter la decisión de la controversia a un particular de confianza común entre los contendientes (árbitro) a cuya decisión las partes se obligan por contrato a atenerse. Del arbitraje facultativo, al cual los contendientes recurren solamente si están de acuerdo en preferir la solución arbitral al uso de la fuerza privada, y en el que la decisión del árbitro es obligatoria solo en cuanto es aceptada por las partes, se pasa al arbitraje obligatorio en el sentido de que los contendientes están obligados por la autoridad a recurrir a él, y que la obligatoriedad de la decisión se impone también con la fuerza del Estado. De aquí a la institución de los jueces públicos el paso es corto: cuando el Estado en lugar de limitarse a imponer a los contendientes el recurrir a los árbitros privados, asume directamente la función plena de garantizar el derecho, mediante órganos propios investidos de pública autoridad, a los cuales los particulares están obligados a recurrir para la composición de las controversias, la jurisdicción como función del Estado ha nacido ya».

El Arbitraje no nace, pues, como una alternativa a la facultad jurisdiccional del Estado moderno de derecho. Habiendo sido el antecedente fáctico de éste, hoy es una fórmula procesal remanente de marcados y propios perfiles en un ámbito específico del Derecho procesal. Históricamente nace como una fase anterior al desarrollo del proceso jurisdiccional y que, con posterioridad a la formación del Estado-nación o Estado de derecho a finales del siglo XVIII, se hace tarea exclusiva y excluyente del Estado, quien se convierte así en el exclusivo Arbiter de los conflictos sociales e individuales de sus ciudadanos.

Sin embargo, el Arbitraje se mantiene como figura jurídico-procesal válida para la solución definitiva de determinadas controversias en las que el Estado cede su posición exclusiva y excluyente permitiendo que sus ciudadanos obtengan la satisfacción a sus conflictos de un modo consensualmente judicializado. Pero sólo en aquellas actividades que el Estado lo permita y bajo la tutela de éste, tanto como se permite la renuncia a los derechos judiciales, la conciliación de éstos, la transacción o su negociación. 
Sin embargo, tal vez por la grave crisis del sistema judicial a nivel mundial en la sociedad contemporánea, muchos han vuelto sus ojos hacia el Arbitraje tejiendo una serie de mitos sobre su realidad, y otorgándole una calidad que ni tiene ni le corresponde, y que a la larga más que beneficiarle le restará fortaleza como adecuado mecanismo antecedente de solución de conflictos entre los particulares.

En efecto, el Arbitraje no puede ser considerado como una alternativa al proceso judicial, porque no lo es, ni por historia ni por realidad; como tampoco lo son el desistimiento de los derechos o la transacción judicial. Son mecanismos antecedentes de solución de conflictos que el Derecho procesal contiene de sus múltiples variables, en donde el proceso judicial jurisdiccional es el modo final, terminal, de lograr la solución compuesta por el Estado a falta de voluntad de los litigantes.

$\mathrm{Y}$ es precisamente eso lo que diferencia el Arbitraje del proceso judicial: la voluntad. En efecto, para renunciar a un derecho, para transigir con él, para arbitrar, se requiere de la voluntad expresa de hacerlo, sin la cual no se puede ingresar válidamente a ninguna de estas figuras. Así como no existe el "desistimiento forzado", ni la "transacción compulsiva", tampoco puede subsistir el «arbitraje obligatorio" porque dejaría de ser Arbitraje para convertirse en liso y puro proceso judicial jurisdiccional, solo que mentiroso.

Para mantener el Arbitraje -evidente institución procesal que, sin embargo, en la versión final del Código Procesal Civil del Perú de 1993 se la contiene ${ }^{8}$ en su verdadera dimensión, y con la fuerza jurídica que

8 Nótese que el Código Procesal Civil del Perú fue inicialmente aprobado por Decreto Ley No 768 de 29 de febrero de 1992, y publicado en el Diario Oficial «El Peruano» el siguiente 4 de marzo, allí se contenía -en su Libro Segundo, arts. $841^{\circ}$ a $931^{\circ}$ - a la denominada Justicia Arbitral. Sin embargo, su primera vacatio legis estableció que ingresaría en vigencia el 1 de enero de 1993, y ello fue postergardo hasta el 28 de julio de 1993. En el ínterin, mediante Decreto Ley $N^{\circ} 25940$ -expedido en la fase dictatorial del Gobierno del Presidente Fujimori después del Golpe de Estado de 5 de abril de 1992- se le modificó sustantivamente, generando la necesidad de un Texto Único Ordenado, que es la versión actual aprobada por Resolución Ministerial No 010-93-JUS. En ese texto final desapareció, sin mayor explicación, el Libro Segundo Justicia Arbitral que luego fue regulado, con algunas modificaciones, como Ley General de Arbitraje, mediante Decreto Ley $N^{\circ} 25935$ (D), de 09 de diciembre de 1992, y que prontamente fue derogada de modo integral y reemplazada con el mismo epígrafe por la Ley $\mathrm{N}^{\circ} 26572$ en actual vigencia. 
le corresponde, debe tenérsele en el lugar que le corresponde, sin desdibujar sus contornos y falsear sus alcances, porque de ese modo no se hace otra cosa que debilitarlo. Uno no puede arbitrar la validez de su matrimonio, ni la determinación de su herencia, ni su divorcio, ni todos aquellos derechos que la ley explícitamente excluye del Arbitraje (la gran mayoría). Tampoco el Arbitraje puede reemplazar a la justicia penal, ni a la justicia constitucional. Entonces, ¿qué es lo que se puede someter al Arbitraje?: fundamentalmente los derechos patrimoniales y que sean de libre disposición de los ciudadanos. Nada más.

Pero ello que parece poco desde un punto de vista conceptual, es bastante en la realidad. El proceso Arbitral reemplaza al proceso judicial del Estado. La decisión arbitral (Laudo) equivale a una sentencia judicial, y el laudo final constituye cosa juzgada para sus protagonistas, sustrayéndose el conflicto o litigio (materia arbitrable) de la competencia de la justicia ordinaria, la que para ese caso específico deviene incompetente en su juzgamiento por sobre el convenio arbitral.

Y lo que es más importante: los árbitros designados válidamente por los contendores devienen en verdaderos jueces jurisdiccionales, pero sólo delegados para el caso concreto de que trate el arbitraje y por el plazo que allí expresamente debe consignarse; tan jueces como los jueces de la justicia común, con la misma representación estatal que la ley les reconoce y con las mismas responsabilidades e incompatibilidades. No podría ser de otro modo.

No existe, pues, una jurisdicción arbitral propiamente dicha como erradamente lo establece la Constitución de 1993, repitiendo el error conceptual de la anterior de $1979^{\circ}$. La explicación que a ello se ha dado, antes y ahora, se expresa en función del presunto fortalecimiento y respeto de esta institución por el hecho de estar dentro del texto

9 Constitución de 1979(D); «Art. 233‥- Son garantías de la administración de justicia:

1.- La unidad y exclusividad de la función jurisdiccional. No existe ni puede establecerse jurisdicción alguna independiente con excepción de la arbitral y la militar. $[\ldots] »$.

Constitución de 1993; "Art. $139^{\circ}$.- Son principios y derechos de la función jurisdiccional:

1.- La unidad y exclusividad de la función jurisdiccional.

No existe ni puede establecerse jurisdicción alguna independiente, con excepción de la militar y la arbitral. [...]". 
constitucional $^{10}$. A ese paso y con la misma metodología, casi todo el país debería estar consagrado en la Constitución. No nos parece que esa deba ser la manera más adecuada en que se habrá de fortalecer y hacer efectiva una institución que permite reconducir válidamente los conflictos individuales y colectivos de la sociedad hacia las mismas soluciones pacíficas que son norte del proceso judicial jurisdiccional. Son su verdadera ubicación, conceptualización, educación, respeto y comprensión lo que habrá de permitir al Arbitraje constituirse en sólida válvula antecedente, manejada por los propios ciudadanos, para la composición pacífica de algunos de sus más grandes quebraderos de cabeza. Siempre que lo deseen claro está.

\section{Naturaleza jurídica del arbitraje y de la conciliación}

Ha sido relativamente difícil ubicar a la institución del arbitraje en una clara definición desde la ciencia del proceso. La doctrina suele pasar a su descripción, a su finalidad o ha sido captada por definiciones que surgen del Derecho civil o, más específicamente, desde el Derecho de los contratos o de las Obligaciones. Sin embargo, queda claro que el Arbitraje y la Conciliación son, esencialmente, instituciones procesales, desde que tienen el mismo origen, cumplen la misma finalidad y se sirven de las mismas categorías básicas para su realidad.

Son, pues, estas instituciones, formas pacíficas de solución de controversias en la sociedad, permitiendo mediante actos concatenados y

10 Andrés Aramburú Menchaca. "Notas al margen de la Constitución»; Concytec; Lima, 1990. Es interesante señalar que este autor, constituyente de 1978 y proclamado autor de esta cláusula constitucional, señaló bajo el epígrafe El Arbitraje Comercial, lo siguiente: "Al discutirse el artículo $233^{\circ}$ [de la Constitución de 1979(D)] hubo un intenso debate técnico-jurídico en la Asamblea Constituyente. Como se ha dicho, el artículo citado considera los arbitrajes como una jurisdicción independiente del Poder Judicial. Por eso la Constitución se refiere a la "jurisdicción arbitral" y creemos que esto es lo apropiado. Sin embargo, distinguidos procesalistas sostuvieron que el arbitraje sólo era un procedimiento, un juicio de naturaleza especial, como otros que considera el Código de Procedimientos Civiles. Triunfó la primera tesis y no seguiremos tratando ahora el punto porque existen otras teorías. Hoy impera lo que la Constitución preceptúa y esta prima sobre todas las leyes. $[\ldots]$ ". 
sistémicos (pro-caedere), llegar a una solución que sea definitiva, definitoria y con calidad de Res Iudicata, eludiendo o evitando el proceso judicial jurisdiccional del Estado, pero dentro de la misma tutela del Estado -de hecho, permitida por éste- dentro del mismo sistema de justicia. Por ello, comparten los elementos esenciales del Debido proceso legal y de la tutela judicial efectiva, ocupando un importante rol y lugar dentro del Derecho jurisdiccional.

Hay, sin embargo, una primera gran diferencia que suele llevar a confusión, y una segunda gran limitación que suele soslayarse. En efecto, la primera gran diferencia entre el proceso arbitral del sistema jurídico y el proceso judicial jurisdiccional radica en que el primero, basado en la ley y permitido por el sistema judicial, pasa por una realidad contractual que le da nacimiento y origen a cada proceso arbitral, y donde bajo los principios procesales de la liberalidad de las formas y de la composición de las partes debe prevalecer por sobre la composición judicial, las partes intervinientes «escogen» a sus jueces (a los árbitros), definen la materia válidamente arbitrable, determinan la mejor forma procesal aplicable al caso (hacen su proceso) y fijan el plazo del mismo. La gran limitación surge precisamente de allí mismo: sólo será procedente (admisible, viable y válido) para aquellos derechos civiles y comerciales de libre disponibilidad, básicamente de orden patrimonial. De allí que no se pueda hablar con propiedad del Arbitraje como medio o forma "alternativa», pues tal no existe: no se puede escoger entre la alternativa de arbitrar o litigar, pues en la mayoría de los casos que el derecho plantea tal alternatividad no existe: así, no se puede arbitrar un divorcio, ni los derechos de familia, ni los de los menores, ni los personalísimos, ni los que corresponden a los Derechos fundamentales de las personas, ni los de responsabilidad criminal regidos por las leyes penales que llevan una condena criminal, etc. Bien visto, el Arbitraje se establece como posibilidad en un universo limitado, pero muchas veces cualitativa y cuantitativamente importante que justifica $-\mathrm{y}$ permite- su realidad, pues representa un costo más elevado que el ordinario para el litigante interesado. $Y$ asimismo, tampoco se podrá arbitrar contra la voluntad de la contraparte, de no mediar pacto previo (en sus distintas acepciones de cláusula compromisoria, compromiso arbitral, pacto arbitral, contrato arbitral, etc.), o pacto posterior, no se podrá compeler por ningún medio lícito ni jurídico a arbitrar, de no mediar expresa anuencia, sometimiento o siempre que, además de dicha expresa vo- 
luntad, la materia arbitrable sea lícita para tal propósito.

Ogayar y Ayllón es, quizás, uno de los que mejor define esta situación, cuando señala que:

«Pero, para resolver los conflictos o contiendas entre particulares, existen diversos medios, pues, además de acudir a los tribunales estatales [...], hay veces que la solución se logra sacrificando una de las partes su posición, abdicando de su pretensión o de la resistencia que venía oponiendo a la pretensión ajena, mediante la renuncia de su derecho; o las partes se hacen concesiones reciprocas para poner fin al litigio, o para impedir que éste surja, por la transacción, o, sin ponerle fin, se conviene que las diferencias se resuelvan no por los órganos jurisdiccionales del Estado, sino por un organismo extraoficial que se denomina arbitraje, pues el Estado, respetuoso con la libertad que concede a los ciudadanos para disponer de sus intereses, la lleva a sus últimas consecuencias [...], permitiendo que las resoluciones de los procesos civiles en los que no haya implícito un interés público, se entregue por ellos, no a los tribunales estatales, sino a jueces privados, facultad consagrada en las legislaciones desde una antigüedad bastante remota, porque el Estado [...] al ejercer la tutela jurídica sobre los ciudadanos, así puede valerse de funcionarios que, en todo caso, asumen la potestad jurisdiccional como de personas a quienes concurriendo determinadas circunstancias, atribuye la facultad de juzgar para un caso concreto ${ }^{11}$.

En consecuencia, el Arbitraje es un proceso judicial -en tanto forma trilateral heterocompositiva- de orden privado, bajo la autoridad del Estado, y que surge de un necesario acuerdo de voluntades, expreso o tácito, para dirimir una o más controversias ante un tribunal ad-hoc, convocado por el consenso de las partes y protegido por el sistema judicial, con decisiones ejecutoriadas y con calidad de Res Iudicata (Cosa juzgada material).

Por su lado, Merchan-Alvarez ${ }^{12}$ que:

11 Tomás Oyagar y Ayllón. El Contrato de Compromiso y la Institución Arbitral; Ed. Rvta, de Derecho Privado-Edls. de Derecho Reunidas, Madrid, 1977; pp. 63-64.

12 Antonio Merchan Alvarez. El Arbitraje. Estudio histórico jurídico; Publicaciones de la U. De Sevilla; Utrera, 1981. 
«Pero, además, de estos cuerpos normativos se deduce una considerable equiparación entre la figura del árbitro y la figura del juez, es decir, que podemos afirmar que los árbitros en líneas generales se tienen en la mente del legislador como unos jueces más. [...].Por eso cuando el maestro Jacobo en su Doctrina nos habla de "De los jueces ordinarios et de quantas maneras que son judgadores" afirma "que son tres maneras dellos. La primera es los ordinarios. Et la segunda de los delegados. Et la terçera de los árbitros" [...] "terçera manera de judgadores [...] son los árbitros a que dizen en latín juez de abenencias [...]”.

Y por su parte, el procesalista italiano Carnacini1 ${ }^{13}$, señala por su lado:

"Así contemplado a grandes rasgos el arbitraje ritual, [...], se presenta como el instituto en que se concede al particular, en mayor medida posible, que contribuya con su obra al ejercicio de aquella función que, en atención al fin que persigue y al resultado que lleva, no puede menos que llamarse jurisdiccional».

En el caso de la Conciliación la institución reproduce las mismas características básicas respecto del Arbitraje. Así, por Conciliación se entiende, al decir de Guzmán Barrón ${ }^{14}$ :

«El proceso por el cual dos o más personas en conflicto logran restablecer su relación, gracias a la intermediación de un tercero denominado conciliador.

El conciliador es un facilitador de la comunicación, no ejerce la función de juez, ni de árbitro. Por ello, para los abogados esta tarea resulta más difícil que para las demás personas, dado que están acostumbrados a buscar las posiciones de las partes y aplicar la ley, por encima de la razón de las partes".

Resulta claro que el proceso de Conciliación, en esencia trilateral y heterocompositivo comparte las características básicas de la estructu-

13 Tito Carnacini. Arbitraje; EJEA, Bs. As., 1961; p. 27 y ss.

14 César Guzmán Barrón. "La Conciliación: principales antecedentes y características»; en DERECHO-PUC N. 52, Rev. de la Fac. de Der., PUC del Perú; Lima, Dic.1998-Abr.1999; p. 67 y ss. 
ra y fundamento del proceso judicial arbitral o jurisdiccional. Las diferencias están en la forma del resultado, pues el conciliador no puede imponer la fórmula de solución en el sentido clásico en que se impone la autoridad de un fallo, aún el del laudo, pero el acuerdo de las partes -cuando se logre- tendrá el mismo valor y efecto que una sentencia judicial, que un laudo o que un acuerdo de transacción debidamente perfeccionado, con plena autoridad de Res Iudicata, dando fin al conflicto que le dio origen, y eliminando del mundo del derecho el conflicto intersubjetivo y/o la incertidumbre jurídica que enfrentó en su momento a sus partes.

Y el conciliador también deberá ser un tercero imparcial, aceptado por las partes o designado por la ley, con las mismas características y obligaciones que el juez judicial o el árbitro privado. Por eso es que la Conciliación pertenece al rubro de los procesos heterocompositivos, como lo precisa Ovalle ${ }^{15}$, cuando señala que:

"[...] el tercero ajeno a la controversia puede asumir un papel más activo, consistente en proponer a las partes alternativas concretas para que resuelvan de común acuerdo sus diferencias. En esta hipótesis, el tercero asume el papel del conciliador y a su función se le denomina conciliación. El conciliador no se limita a mediar entre las partes, sino que les debe sugerir fórmulas específicas para que puedan llegar a un convenio entre ellas. Para que el conciliador pueda desempeñar eficientemente su función, es indispensable que conozca la controversia de que se trate, a fin de estar en condiciones de proponer alternativas razonables y equitativas de solución.

Pero la función del conciliador se limita a proponer posibles soluciones, cuya adopción queda sujeta, en todo caso, a la voluntad de las partes. Éstas pueden aceptar o rechazar las propuestas del conciliador. Por ello, en la conciliación, al igual que en la mediación, la solución del litigio depende, finalmente, de la voluntad de las partes. Esta es la razón por la que se considera que la mediación y la conciliación tienen, en realidad, una posición intermedia entre la autocomposición y la heterocomposición". 


\section{Regulación legal del arbitraje en el Perú}

El proceso arbitral no ha sido desconocido para la legislación peruana desde antiguo, aun cuando sin la necesaria bondad técnica. Así, por ejemplo, en el Código de Procedimientos Civiles de 1912(D), a principios del siglo pasado, se regulaba el arbitraje bajo el epígrafe «juicio arbitral" regulado en el Título $\mathrm{V}$ de su sección segunda. Allí se consignaba en su original Art. $548^{\circ}$ lo siguiente:

«Art. $548^{\circ}$.- Toda controversia, sea o no materia de juicio, puede someterse a la decisión de uno o más árbitros. El número de éstos será siempre impar".

Los arts. $549^{\circ}$ a $582^{\circ}$ desarrollaban, a partir de allí, el proceso de formalización judicial del arbitraje cuando éste hubiere sido pactado y las partes no cumplieran con formalizarlo, los requisitos de la materia arbitrable, la capacidad para conferir válidamente éste, la imposibilidad del arbitraje de las pretensiones del Estado y demás instituciones de carácter oficial, la formalidad del compromiso arbitral o del compromiso para arbitral, la sede, el carácter de equidad o de derecho, las condiciones para recurrir, las causales de anulación del laudo y la forma de conformación del mismo en defecto de la aceptación de las partes. Asimismo, esas reglas resultarán aplicables por supletoriedad a todo proceso arbitral instaurado en defecto de norma arbitral expresa, y por la vía de conexión, todo el Corpus Iuris mismo Código de Procedimientos Civiles de 1912(D), especialmente en la figura del entonces llamado juicio ordinario, que era el esquema procesal más lato que dicho ordenamiento legal preveía.

El Código Civil de 1936(D) guardó silencio absoluto sobre el Arbitraje, y ninguna de sus estipulaciones de obligaciones o del Derecho de los contratos hizo referencia a este instituto.

La Constitución Política del Perú de 1979(D), que estuvo vigente desde el 28 de julio de 1980 hasta el 31 de diciembre de 1992, sí tuvo -como ya se ha señalado líneas arriba, crf. cit. No. 10, Op. cit.- referencia expresa al arbitraje, al definir, dentro de las Garantías constitucionales de la administración de justicia en su Art. $233^{\circ}$, Inc. 1ero., dentro del Capítulo IX del Poder Judicial, a la denominada «jurisdicción arbitral», equivocadamente como jurisdicción de excepción al igual de 
la justicia militar, y como si estuviese fuera del control judicial de los tribunales ordinarios. Todo ello, como ya se señaló en su oportunidad, no reflejaba ninguna bondad técnica, ni tenía respaldo en doctrina procesal alguna y, más bien, tuvo como paradójico propósito «encerrar" $y$ "definir" en el texto constitucional al instituto del Arbitraje a fin de forzar a su regulación legal por el legislador y forzar a su respeto por parte de la administración de justicia estatal. En efecto, en su momento se dijo que ${ }^{16}$ :

«Hay sólo, señala taxativamente la Constitución, dos excepciones a esta regla general: la jurisdicción militar que se rige por la Ley Orgánica de la Justicia Militar y el Código de Justicia Militar como rezago moderno de un típico "fuero de casta" que se mantiene vigente en la mayoría de las naciones y que está referido al juzgamiento del personal militar en servicio y solo por los actos del servicio o función militar, siendo por tanto un fuero privativo en razón de la actividad pública del Estado que realizan los funcionarios militares. La segunda está referida a la denominada "jurisdicción arbitral" que en puridad no es una jurisdicción diferente a la del Poder Judicial. Sin embargo, las excepciones a la regla general no están a su vez exceptuadas del cumplimiento de las garantías constitucionales de la administración de justicia ni de los principios básicos del debido proceso legal, de tal modo que no podrá existir juzgamiento militar válido, ni soportable por nuestra estructura constitucional (recordemos que las dos excepciones están igualmente sometidas a la autoridad de la Constitución) si es que en su realidad se han cumplido las reglas esenciales del juzgamiento justo que precisamente la Constitución y los pactos internacionales prescriben de modo imperativo. $\mathrm{E}$ igual principio debe regir también en las reglas procesales que terminen siendo pactadas dentro de un compromiso arbitral».

El Código Civil de 1984, en actual vigencia, derogó el Código Civil de 1936(D), y promulgado el 14 de noviembre de ese año, trajo como novedad en el Título XI de la Sección Segunda, Contratos Nominados, de su Libro VII, Fuentes de las Obligaciones, la referencia a la Cláusula

16 Aníbal Quiroga León. «Las Garantías Constitucionales de la Administración de Justicia»; en: La Constitución diez años después; AAVV; Fund. Naumann y Const. \& Soc., Lima, 1989; p. 307 y ss. 
Compromisoria y Compromiso Arbitral, entre los numerales 1906 a 1922, y que a la fecha se encuentran íntegramente derogados ${ }^{17}$. Es importante observar cómo la Comisión Revisora del Código Civil, que trabajó por varios años para reformar el principal cuerpo jurídico civil, y donde no hubo ningún procesalista presente, se abocó a legislar sobre esta institución, a la cual, además, ni se le reconoció ni se le aceptó carácter procesal alguno.

Así, en el Capítulo Primero, Cláusula Compromisoria, en los arts. $1906^{\circ}$ a $1908^{\circ}$, se regulaban las características (como contrato preliminar) y la formalidad (pacto principal o estipulación accesoria, pacto a futuro y materia arbitrable) y su efecto vinculante ante el Poder Judicial.

En el Capítulo Segundo, Compromiso Arbitral, arts. $1909^{\circ}$ a $1922^{\circ}$, se regulaba al compromiso arbitral, su naturaleza, definición, solemnidad (por escrito), tanto cuando es fuera de proceso o cuando se hace dentro del proceso (petición escrita suscrita por ambas partes con firmas legalizadas por el secretario de la causa). Asimismo, su contenido, sanciones en caso de incumplimiento, libertad de los árbitros para fijar las costas, materias no arbitrables (en el caso del Estado y sus bienes, con excepción de las empresas de derecho público o estatales o de economía mixta, en cuyo caso el compromiso arbitral debía ser previamente aprobado por Resolución Suprema), la regulación del arbitraje de derecho o el de conciencia (presumiéndose a falta de acuerdo expreso en contrario, que el arbitraje debía de ser derecho), la obligatoriedad de designar árbitros letrados reconocidos como tales por el ordenamiento jurídico peruano, necesariamente abogados, salvo en el caso de los árbitros de consciencia (que el Código denomina impropiamente con evidente confusión "amigable componedor») en que la designación podía recaer en personas naturales nacionales o extranjeras mayores de veinticinco años con pleno ejercicio de sus derechos civiles; y, en ambos casos, la necesidad de su número impar, los impedimentos para ser árbitro, el funcionamiento del tribunal arbitral colegiado, las obligaciones y deberes básicos de los árbitros y las causales de extinción del compromiso arbitral. Se termina con una necesaria referencia genérica a la aplicación supletoria del Código de Procedimientos Civiles de 1912(D) en cuanto al proceso arbitral en aquello no previsto por el Código Civil.

17 Primero por la Primera Disposición Final del Decreto Ley $\mathrm{N}^{\circ} 25935$, y luego esta norma por la actual Ley General de Arbitraje $\mathrm{N}^{\circ} 26572$. 
Hemos dejado para el comentario individual la norma dispuesta en el Art. $1914^{\circ}$ del Código Civil de 1984, ahora derogada, pues constituye una disposición eminentemente procesal que amerita una disgregación individual y que señalaba lo siguiente:

"Art. 1914‥- La existencia de la cláusula compromisoria y del compromiso arbitral puede ser invocada como excepción por cualquiera de las partes».

Resulta evidente la falta de bondad técnica de esta previsión procesal, que da el mismo pie de igualdad a la cláusula compromisoria y al compromiso arbitral, no obstante que la propia normatividad del Código Civil le tratan como diferentes. Por otro lado, a creación de una nueva figura de "excepción procesal" (en este caso la que fue llamada excepción de arbitraje) no guarda relación técnica con las excepciones materia de un proceso judicial, pues bien, la existencia de un pacto arbitral o de un compromiso arbitral (cualquiera sea su naturaleza o la denominación que reciba) determina la incompetencia material de la autoridad judicial ordinaria, para ceder paso a la autoridad de la voluntad de las partes que, con la expresa autorización legal, determinan que legítimamente su controversia sea definitivamente resuelta por un Tribunal Arbitral colegiado o unipersonal. Ello genera de modo ineluctable la incapacidad materia (incompetencia por razón de la materia) del órgano jurisdiccional para dirimir válidamente tal controversia en contravención a lo que resuelva de modo previo el Tribunal Arbitral que, conforme al mismo pacto, se instale, laudando la misma de modo definitivo y definitorio (Res Iudicata). Los actos procesales que realice la autoridad judicial en contrario al acuerdo expreso de las partes en tal sentido serían, por ende, nulos de pleno derecho, siempre que ello se le haga saber en la forma o modo oportunos.

Entonces no hacía falta "crear» una nueva figura procesal inexistente (excepción arbitral), confusa por lo demás, pues hubiese bastado señalar que «la existencia de la cláusula compromisoria o de un compromiso arbitral válidamente otorgado determina la incompetencia del juzgador".

La Constitución de 1993, que derogó la Constitución de 1979(D) luego de un proceso político complicado y conflictivo, repite literalmente la formulación de su predecesora, e ingresó en vigencia luego de 
un proceso de Referéndum el lero. de enero de 1993, manteniéndose vigente desde entonces hasta la fecha, y allí se hace referencia expresa al arbitraje, al definir nuevamente, como de las garantías constitucionales de la administración de justicia en su Art. $139^{\circ}$, Inc. 1ero., -aún cuando allí se le denomina "Principios y Derechos de la función jurisdiccional», dentro del Capítulo VII, Poder Judicial, a la nuevamente denominada "Jurisdicción Arbitral", como jurisdicción independiente, de excepción, al igual de la Justicia militar, y como si estuviese. Como aquella, fuera del control judicial de los tribunales ordinarios. Como ya se ha dicho líneas arriba, con relación a la Constitución de 1979(D) sin reflejar bondad técnica, ni tener el respaldo en la moderna doctrina procesal, teniendo más bien como paradójico propósito el «encerrar» y "definir" en el texto constitucional al instituto del Arbitraje a fin de forzar a su regulación legal por el legislador y forzar a su respeto por parte de la administración de justicia estatal. No se discute la importancia del Arbitraje como tal, menos aún en la hora actual del casi total fracaso y colapso de los sistemas de administración de justicia en la sociedad contemporánea; pero si criticamos el que no se haya hecho esto del modo más adecuado, quizás dentro de las mismas "garantías constitucionales de la administración de justicia", la necesidad de revalorar y relanzar el Arbitraje como una forma pacífica de solución de controversias (quizás más pacífica -si cabe la expresión- que el proceso judicial jurisdiccional) por el manejo y presencia de las partes sobre su proceso, por la mayor confianza y certeza en la labor de los árbitros y, en suma, por ser un proceso ad-hoc generado y creado y fraccionado por las partes antes que el proceso judicial ordinario que en forma seriada ofrece el Estado hoy, no siempre con la bondad y resultados que la sociedad espera para la consecución de la ansiada paz social que tanto reclamó Couture ${ }^{18}$ para ello, más allá de la mera satisfacción de las partes interesadas en la composición del litigio o controversia.

Así las cosas, al derogarse todo el Libro Segundo, Justicia Arbitral, del novísimo Código Procesal Civil de 1993, mediante el Decreto Ley $\mathrm{N}^{\circ} 25935(\mathrm{D})^{19}$, aún antes de haber éste entrado en vigencia, desapa-

18 Aníbal Quiroga León. "Conceptos Básicos en el Estudio del Derecho Procesal: a propósito de la Ciencia del Proceso»; en DERECHO No 40, Rev. de la Fac. de Derecho de la PUC del Perú, Lima. Dic. 1986; p. 243 y ss.

19 La primera de las Disposiciones Finales de esta norma legal estableció que: 
reció la regulación del Arbitraje en este Corpus Iuris, quedando únicamente subsistentes las referencias señaladas en los arts. $446^{\circ}$, Inc. 13 , $448^{\circ}, 450^{\circ}$ y $451^{\circ}$, Inc. 5 del TUO del Código Procesal Civil, en donde se señala la procedencia en juicio de la ahora denominada Excepción de Convenio Arbitral, y donde se regula la procedencia de la misma únicamente cuando exista el documento que acredite su existencia, la precedencia de la misma frente a las demás, cuando se la deduce en con-

"Primera: Deróganse los artículos $1906^{\circ}$ a $1922^{\circ}$ del Código Civil, el Libro II del Código Procesal Civil, aprobado por Decreto Legislativo $N^{\circ} 768$ y las referencias al "Libro Primero de Justicia Civil" en dicho Código, asi como la Vigésima, Vigésimo Primera y Vigésimo Segunda Disposiciones Finales del mismo». Ver además, cit. No 8 supra.

Esta misma falta de coherencia en la regulación de la denominada "Justicia Arbitral», y su completa derogación antes de la puesta en vigencia del Código Procesal Civil, junto con otras tantas normas del flamante Código Procesal Civil, que han dado lugar a que hoy exista un Texto Único Ordenado aprobado por Resolución Ministerial del Ministerio de Justicia, puede encontrarse en parte de su presentación, titulada "Exposición de Motivos" en la parte que señala: "[...] No pueden mantenerse instituciones procesales que tienen su origen en la Edad media y parentesco con las Siete Partidas. Los anaqueles del Poder Judicial son elocuentes testigos de la farragosa tramitación a que han estado y están sujetos los procesos civiles. Litigios hay que duran décadas. Nuestros jueces y abogados están acostumbrados a la rutina de pleitos inacabables, en que las partes en conflicto son sustituidas, con frecuencia, por sus herederos. La pereza mental induce al facilismo y, como consecuencia, a la declaratoria de nulidad de muchos juicios, con años de tramitación, por fallas o vicios procesales. $\mathrm{El}$ abuso de los recursos prolonga los pleitos con perjuicio de los derechos sustantivos y con el descrédito de la administración de justicia. [...] Otras Comisiones, designadas por el Poder Ejecutivo, con más tiempo, tampoco culminaron el empeño. Sin embargo, dejaron útiles aportes. Por encima de mezquindades, de egoísmos y de incomprensiones, la Comisión revisora del Código Procesal Civil, ha culminado su tarea. Quienes integramos la Comisión tenemos el convencimiento que el proyecto tiene, como toda obra humana, defectos, omisiones, imperfecciones. Asumimos la responsabilidad plena de las deficiencias. A medida que la experiencia acredite la necesidad de introducir correcciones, los legisladores viabilizarán (sic) a mejora del Código. Pero las bondades de la novísima (sic) legislación procesal se advertirán [a] poco de su vigencia. [...] Habrá un debate, tras la promulgación del Código y antes de su vigencia. Ojalá se adviertan los errores para subsanarlos. Los frutos del Código Procesal Civil serán generosos. Los que osaron oponerse a su aprobación, pronto estarán arrepentidos (sic). Al Presidente de la República, con el voto del Consejo de Ministros le corresponde adoptar la decisión más adecuada al interés del Perú. [...]". 
junto con otras excepciones procesales y cuando se regulan los efectos de la decisión que la acoge, determinándose por ello que en tal caso al igual que en el caso de la excepción de incompetencia- el juez de acogerla deberá anular todo lo así indebidamente actuado en el ámbito judicial, dándose por concluido el proceso judicial iniciado en contravención al pacto arbitral que debe ser previo y constar por escrito.

Quizás las características más saltantes del Decreto Ley Nº 25935(D), denominado Ley General de Arbitraje bastante más completa e integral que la regulación prevista en el Libro II del Código Procesal Civil-que nunca entró en vigor- fueron las siguientes:

a) La definición del Convenio Arbitral como un contrato previo, solemne (arts. $4^{\circ}$ a $15^{\circ}$ );

b) La determinación de que la integración o formalización judicial del arbitraje, y sus reglas, sobre la base de un Convenio Arbitral no honrado por las partes, debe hacerla el Juez Civil señalado por las partes, o el del lugar en donde éste deberá realizarse, o del lugar de celebración del Convenio, o el del lugar del domicilio del demandado, o de cualquiera de ellos si fueran varios;

c) La presunción de que, en defecto de pacto expreso, el Arbitraje deberá ser derecho;

d) En cuanto a los árbitros, (arts. $16^{\circ}$ a $25^{\circ}$ ), se establece que en el caso de los arbitrajes de derecho, estos deberán llevarse a cabo por árbitros letrados conforme a las leyes peruanas, debidamente Colegiados (defensa cautiva);

e) La prohibición de deferir a una sola de las partes la designación de la totalidad de los árbitros;

f) En cuanto al proceso arbitral en sí mismo, (arts. $26^{\circ}$ a $34^{\circ}$ ) se estableció la libertad de las formas;

g) La posibilidad del arbitraje administrado, a cargo de instituciones especializadas para el efecto, frente al arbitraje de partes;

h) La posibilidad de que el proceso arbitral concluya por Conciliación, Transacción, Suspensión del Proceso Arbitral, Renuncia al Proceso Arbitral y Desistimiento del Proceso Arbitral (arts. $35^{\circ}$ a $37^{\circ}$ );

i) Competencia de los árbitros y su sistema de votación en el caso de los Tribunales arbitrales colegiados;

j) Las características del Laudo (arts. $42^{\circ}$ a $51^{\circ}$ ); 
k) Los recursos de apelación cuando su procedencia haya sido pactada su procedencia (arts. $52^{\circ}$ a $54^{\circ}$ ), sea ante una segunda instancia judicial, sea ante una segunda instancia arbitral expresamente pactada;

1) El recurso de anulación de Laudo (arts. $55^{\circ}$ y $56^{\circ}$ ), en las causales numerus clausus allí expresamente previstos;

m) Las medidas cautelares y de ejecución del laudo (arts. $73^{\circ}$ a $80^{\circ}$ );

n) El arbitraje internacional (arts. $81^{\circ}$ a $107^{\circ}$ ), su definición y características; $y$,

o) El reconocimiento y ejecución de laudos arbitrales provenientes de arbitrajes internacionales.

A los escasos tres años de vigencia de la comentada norma legal, sin mayor explicación ${ }^{20}$. Ésta a su vez fue íntegramente derogada y sustituida por la Ley No 26572, también denominada Ley General de Arbitraje, de 5 de enero de 1996, y que reguló nuevamente por completo todo el Proceso Arbitral en 124 artículos, ocho disposiciones complementarias y transitorias, tres disposiciones modificatorias y dos disposiciones finales.

Esta norma legal, siguiendo la moderna técnica legislativa, aparece ahora debidamente sumillada a diferencia de lo normado originalmen-

$20 \mathrm{El}$ auge del Arbitraje empezó a generar doctrina, instituciones habilitadas, mayor cobertura y difusión. Esto motivó, en nuestro concepto, el que la tarea se «repartiera» en el seno de la Comisión Revisora del Código Procesal Civil. Así la mayoría se dedicó a este Corpus Iuris, y una minoría al tema del Arbitraje, en un mutuo pacto de apoyo. Esto es más evidente cuando se comparan los textos del Libro Il con respecto al propio Código Procesal Civil -p.e. el Código Procesal Civil se presenta sumillado-, en tanto que su Libro II no lo estaba, además de ser notoria una diferente redacción y utilización de conceptos procesales. Quizás ello explique el porqué de su escisión aún antes de que el Código Procesal Civil ingrese en vigencia. Luego de esta curiosa "división del trabajo», una Resolución Ministerial del Ministerio de Justicia aprobó el denominado Texto Único Ordenado del Código Procesal en la versión que rige hasta ahora -ya sin el Libro II Justicia Arbitral-, en tanto que un Decreto Ley -norma legal con rango de ley que promulga el Ejecutivo, en la sede del Consejo de Ministros, en ausencia del Congreso Nacional en la fase dictatorial del Gobierno Peruano en 1992 luego de un Autogolpe de Estado Institucional que dio paso al autodenominado "Gobierno de Emergencia y Reconstrucción Nacional»-; con lo que se evidencia que ni una ni otra norma se hubiesen podido dictar así, en tales condiciones, sin un apoyo explícito del Ejecutivo de aquella fase dictatorial, de consuno con los mentores de estas dos normas legales. 
te en el Código Procesal Civil, Libro II, Justicia Arbitral, y a lo que se reguló en el Decreto Ley N$^{\circ} 25935$.

Los arts. $1^{\circ}$ al $8^{\circ}$ regulan las Disposiciones Generales, resaltando que:

a) La posibilidad de arbitrar las consecuencias patrimoniales de los fallos judiciales previamente expedidos, para sustraer de la ejecución de una sentencia las materias que sean de libre disponibilidad de las partes interesadas;

b) La regulación del Arbitraje del Estado, con un cambio cualitativo a toda regulación pasada (vr.g. la regulación del Arbitraje en el Código Civil de 1984), sin necesidad de autorización previa especial, entendiendo como Estado al gobierno central y los gobiernos regionales y locales (municipalidades). Se establece que las empresas estatales de derecho privado o de economía mixta pueden acordar libremente, sin necesidad de autorización previa, someterse a arbitraje nacional, con relación a los contratos celebrados con nacionales y extranjeros.

c) Se invierte la presunción en el sentido de que, a falta de pacto expreso, el Arbitraje deberá ser de consciencia o equidad, a menos que expresamente se halla pactado el Arbitraje de Derecho. Y aun en este último caso, cuando el arbitraje verse sobre asuntos de carácter comercial, los árbitros deberán tomar en cuenta los usos mercantiles aplicables a cada caso;

d) Se excluye, a falta de pacto expreso, la intervención del Poder Judicial, sometiéndose de modo exclusivo y excluyente a la denominada jurisdicción arbitral;

e) Se regula el arbitraje administrado a cargo de una institución Arbitral, la que necesariamente deberá instituirse como persona jurídica, dándose a la misma la facultad de nombrar árbitros, el procedimiento y demás reglas con las que administrará el arbitraje, de conformidad con su Reglamento Arbitral;

f) Se abandona definitivamente la diferenciación, clasificación y distinción de Cláusula compromisoria y de Compromiso arbitral, para resumirse en un solo concepto: convenio arbitral, que resulta así regulado en los arts. $9^{\circ}$ a $17^{\circ}$. Así, la definición legal del convenio arbitral es:

"Art. $9^{\circ}$.- Definición de convenio arbitral. El convenio arbitral es el acuerdo por el que las partes deciden someter a arbitraje las 
controversias que hayan surgido o puedan surgir entre ellas respecto de una determinada relación jurídica contractual o no contractual, sean o no materia de un proceso judicial.

El convenio arbitral obliga a las partes y a sus sucesores a la realización de cuantos actos sean necesarios para que el arbitraje se desarrolle, pueda tener plenitud de efectos y sea cumplido el laudo arbitral.

El convenio arbitral puede estipular sanciones para la parte que incumpla cualquier acto indispensable para la eficacia del mismo, establecer garantías para asegurar el cumplimiento del laudo arbitral, así como otorgar facultades especiales a los árbitros para la ejecución del laudo en rebeldía de la parte obligada.

Independientemente de lo dispuesto en el párrafo anterior, los árbitros se encuentran facultados para imponer multas hasta por un máximo de dos (2) Unidades Impositivas Tributarias a la parte que no cumpla sus mandatos. Estas multas que serán en favor de la otra parte, constarán en el laudo arbitral y se ejecutarán conjuntamente con este último".

g) La solemnidad escrita del convenio arbitral se flexibiliza, ya que se señala que por forma escrita no sólo se entenderá cuando éste se celebre por escrito, sino cuando resulte clara del intercambio de cartas, o de cualquier otro medio de comunicación o correspondencia en que inequívocamente se deje constancia documental de las partes de someterse a arbitraje. Ello es mucho más avanzado aún cuando la norma señala que a pesar de no haberse formalizado el convenio arbitral respectivo, el mismo se entenderá perfeccionado cuando una de las partes tomase la iniciativa de comenzar el arbitraje, bajo el conocimiento de uno o más árbitros, y la otra parte acepta la misma, sea expresamente, sea tácitamente apersonándose al proceso arbitral sin objetar tal intervención, en una suerte de convalidación tácita retroactiva;

h) El convenio arbitral podrá tomar la forma de cláusula accesoria, o relación jurídica estándar, y será oponible y exigible, siempre que haya sido conocida o podido ser conocida por la otra usando la diligencia ordinaria, sea en Cláusulas Generales de Contratación o Contratos por adhesión. También se reconoce el Arbitraje estatutario configurado por el convenio arbitral regulado por los Estatutos o 
normas equivalentes en sociedades civiles o mercantiles cualesquiera sea su denominación conforme a ley, asociaciones jurídicas y demás entidades colectivas. Se regula, asimismo, el denominado arbitraje testamentario cuando así lo haya previsto el testador respecto de cualquier controversia surgida o por surgir entre los herederos testamentarios, o de terceros en relación con los bienes de la herencia;

i) Se prevé la separabilidad del convenio arbitral respecto del contrato o convenio que le contenga, de manera que constituyen pactos independientes, donde la inexistencia, anulabilidad, nulidad, resolución, rescisión, etc., de éste, ni afecta a la existencia, validez o exigibilidad de aquel, inclusive para determinar válidamente las condiciones jurídicas del convenio o contrato que contenga;

j) Se insiste nuevamente en el concepto, errado en nuestro criterio, de la denominada excepción de convenio arbitral, de manera tal que el desconocimiento en juicio ordinario de la existencia del convenio arbitral para la solución de la controversia sometida a la justicia ordinaria dará lugar a la oponibilidad de la excepción de convenio arbitral válida de este medio de defensa. Vencido el plazo previsto para este, se entenderá renunciado el derecho a invocarla, y sin efecto alguno el convenio arbitral;

k) Será posible la sustracción de la materia sometida al proceso judicial cuando las partes celebren, en el curso de la misma, un convenio arbitral que deberá ser respetado por la autoridad judicial haciendo caducar el proceso de que se trate y cediendo paso a la instalación del tribunal arbitral de que se trate, bajo las reglas que se pacten para este efecto;

1) El Capítulo de Los árbitros está regulado en los arts. $18^{\circ}$ a $32^{\circ}$, siendo lo más destacable el que los árbitros podrán ser personas naturales o personas jurídicas dentro de una plena libertad para el proceso de su nombramiento, siendo en este último caso nombrada a su vez como entidad nominadora, y cuando se trate de Arbitraje de Derecho deberá recaer en abogados, sea nacionales o extranjeros, sin que estos últimos deban ser necesariamente abogados registrados en el territorio nacional;

m) Se regula, finalmente, un procedimiento judicial expeditivo para la designación judicial de los árbitros de la parte renuente a hacerlo, sin que quede recurso alguno cuando el juez hubiese nombrado al o a los árbitros, y sí con efecto suspensivo cuando lo hubiese negado; 
n) El proceso arbitral se regula entre los arts. $33^{\circ}$ y $40^{\circ}$, bajo el principio de que la libertad de la regulación del proceso -bajo el cumplimiento estricto del principio procesal de que a composición de las partes prevalece por sobre la composición judicial, desmitificando el concepto de la irrenunciabilidad o el carácter público de las normas procesales, siendo alternativo el sometimiento a los reglamentos de las entidades autorizadas a llevar el arbitraje administrado;

o) Se establecen reglas básicas, de funcionamiento supletorio, de la tramitación del proceso arbitral. Dentro de esto, una regla esencial es la contenida en el Art. $39^{\circ}$ en donde, además de la materia arbitrable que las partes conceden en el proceso arbitral, se establece como norma de orden público la facultad inmanente de que los árbitros siempre tendrán la potestad de establecer los límites válidos de su propia competencia, incluyendo la posibilidad de determinar en ello la existencia o inexistencia, eficacia o validez del propio convenio arbitral. Esta facultad podrá exigirse exofficio, pudiendo hacerlo como cuestión previa, o ser ello reservado, por decisión del propio tribunal arbitral, a la expedición del Laudo, no siendo esta decisión susceptible de recurso alguno;

p) También se establece como regla genérica la posibilidad del tribunal arbitral de ocurrir, aún las partes con autorización de éste, a la autoridad judicial para requerir el auxilio judicial en la actuación de los medios probatorios;

q) Las demás normas se refieren a la posibilidad de conciliar o transigir ante los árbitros, quienes deberán ser promotores de estas posibilidades, aún del desistimiento y de la suspensión temporal del proceso arbitral, la competencia de los árbitros y las mayorías para Laudar válidamente, el Laudo arbitral, los costos del arbitraje, los recursos, sea en una segunda instancia arbitral, o ante el Poder Judicial -en la Sala Civil correspondiente de la Corte Superior de Justicia del Distrito Judicial que corresponda- cuando ello haya sido expresamente autorizado por el convenio arbitral o por las reglas pactadas para el mismo, las causales taxativas de anulación del Laudo (Numerus Clausus), y la posibilidad restrictiva del recurso de casación sólo cuando el Laudo haya sido anulado en todo o en parte, donde este recurso extraordinario de impugnación se prevé sólo en defensa del proceso y de la institución arbitral; 
r) Se regulan también entre los arts. $79^{\circ}$ a $87^{\circ}$, con bastante precisión, las providencias cautelares susceptibles de solicitarse en el proceso arbitral, sea en sede judicial, sea en sede arbitral, la ejecución del Laudo y su publicación en diarios o en revistas de la prensa del Laudo a costa del que lo solicite, como sanción moral para la parte que obligó al vencedor a recurrir al Poder Judicial para la ejecución y cumplimiento de lo que haya sido así laudado;

s) También se regula con profusión y prolijidad el Arbitraje Internacional entre los arts. $88^{\circ}$ y $126^{\circ}$ con toda una normatividad propia;

t) Se establece entre los arts. $127^{\circ}$ y $131^{\circ}$ las condiciones del Exequatur de los Laudos extranjeros, las condiciones de su reconocimiento y ejecución;

u) Es interesante destacar, dentro de lo ya señalado al principio de este comentario, que la Primera disposición complementaria y transitoria que toda referencia legal o convencional a una "Cláusula compromisoria" o a un "Compromiso Arbitral" deberá ser reconducida al entendimiento legal de un convenio arbitral, en los términos de los supuestos de hecho de esta Ley;

v) Se estableció también un plazo para la adecuación de los reglamentos arbitrales de las instituciones del arbitraje administrado (sesenta días), y la necesidad de que estas instituciones sean siempre -y tengan la forma de- persona jurídica; $y$,

w) Finalmente, se ordena la creación de juzgados y cortes de justicia de especialidad arbitral para el conocimiento de la designación de los árbitros en defecto del cumplimiento de la parte renuente, y para el conocimiento de los recursos de apelación, cuando esto haya sido pactado, y para conocer el recurso de anulación que esta ley prevé taxativa y restrictivamente.

\section{Regulación legal de la conciliación en el Perú}

El 13 de noviembre de 1997 se publicó en el Diario Oficial «El Peruano" la Ley $\mathrm{N}^{\circ}$ 26872, denominada "Ley de Conciliación». Esta norma legal no está aún en vigencia, pues actualmente se halla bajo prórroga de vacatio legis como consecuencia de las diferentes normas legales que han postergado su aplicación en el tiempo, pues prevista inicialmente para ingresar en vigencia a los dos años de su publicación (14 de enero 
del 2000), la imposibilidad de lograr su aplicación forzosa en todo el territorio nacional ha dispuesto mediante la Ley $\mathrm{N}^{\circ} 27218$ de 12 de diciembre de 1999 que esto ocurra recién, en principio, el próximo 14 de enero del año 2001.

La conciliación es también, al lado del arbitraje, básicamente una figura procesal. Como ya se ha señalado, muchas veces se tiende a pensar -de modo equívoco, por cierto- que lo procesal es siempre litigioso, siempre controversial, siempre guerrero, de manera que figuras como la conciliación deberían estar fuera de lo procesal por ser incompatibles. Si miramos una vez más con detenimiento dentro de la teoría del proceso, y su ciencia, veremos que la conciliación es una de las formas que el proceso nos proporciona un método ordenado, secuencial y lógico para lograr la solución de un conflicto de intereses de manera pacífica. El proceso, y sus variantes, son pues, modos pacíficos de solución de controversias, a mitad de camino entre una fórmula autocompositiva y la forma heterocompositiva. En términos reales, constituye una forma casi anterior de solución procesal a la que provee la heterocomposición procesalizada que está a cargo, de modo exclusivo y excluyente, del Poder Judicial por mandato de nuestro esquema constitucional, y dentro de un esquema de heterocomposición no procesalizada.

Corresponde la Conciliación, en consecuencia, a una etapa anterior a la del proceso judicial jurisdiccional conforme señala la Ley de Conciliación. Esta norma tiene por evidente finalidad el descongestionar al Poder Judicial de un importante número de causas que, bien manejadas por las partes de modo directo, bajo la inducción de un Conciliador como tercero necesariamente imparcial, le impiden actuar dentro de plazos razonables que la ley y el principio de razonabilidad consideran los adecuados para la resolución de una controversia. Se pretende con la implementación y obligatoriedad de esta institución del Derecho Procesal desviar del Órgano Jurisdiccional el aumento innecesario de litigios en nuestra sociedad, bajo una adecuada técnica jurídica de negociación y persuasión, buscando con ello que las partes interesadas en su conflicto, reflexionen acerca de los puntos comunes que les acercan, quitándole la innecesaria litigiosidad y con ello instaurar una "Cultura de Paz» por la cual aquellos particulares que tengan un conflicto de intereses, de modo previo a la solicitud de actuación de la autoridad judicial competente, busquen la posibilidad de arribar a un acuerdo razonable y satisfactorio para ambas. 
Como se podrá apreciar de modo directo con la Ley $\mathrm{N}^{\circ} 26872$, que en el proceso conciliatorio tendrá intervención un tercero cuya misión será la de encaminar el proceso de tal modo que la fórmula conciliatoria a la cual se arribe sea una que imponga un nuevo status jurídico definitivo para las partes, será también función de este tercero proponer alternativas de solución previas a la decisión de acudir al poder judicial.

La obligatoriedad de acudir al proceso conciliatorio antes de ingresar al proceso judicial, y como requisito sine qua non de éste, tiene por finalidad la disminución del ingreso de nuevas causas judiciales cuya tramitación supone un costo tanto para las partes como para el Estado. Ahora bien, esta obligatoriedad se refiere al proceso de conciliación, no así a que las partes deban necesariamente resolver sus controversias. Finalmente cabe señalar, que este rasgo de obligatoriedad que se ha plasmado en la Ley de Conciliación también estará presente en el cumplimiento del acuerdo al cual arriben las partes, pues caso contrario se requerirá el apoyo de la autoridad judicial para su ejecución.

Al igual que la transacción judicial y la transacción extrajudicial, la conciliación judicial o preventiva (como es el caso de la Ley de Conciliación) responden también a la ya señalada moderna denominación de ADR's (Alternative Disputes Resolutions), y cuya impropia traducción al español las señala como "medios alternativos de solución de controversias», constituyen mecanismos anteriores -antes que propiamente «alternativos» - a la solución adecuada de una controversia mediante la posibilidad de que las mismas partes interesadas logren esto evitando la actuación y costo del órgano judicial, y con ello obstar la innecesaria intervención del Estado para la solución de los conflictos jurídicamente relevantes que se den entre sus ciudadanos y que estos mismos, en el contexto de la autonomía y libre disponibilidad de los derechos.

Así, la Ley $\mathrm{N}^{\circ} 26872$, en sus 38 artículos y siete disposiciones complementarias, transitorias y finales, siendo sus aspectos más saltantes, los siguientes:

a) Se declara de interés nacional (SIC) la institucionalización y desarrollo de la Conciliación como mecanismo alternativo (SIC) de soluçión de conflictos; 
b) La Conciliación propicia una Cultura de Paz (SIC), siguiendo los principio éticos de equidad, veracidad, buena fe, confidencialidad, imparcialidad, neutralidad, legalidad, celeridad y economía;

c) La Conciliación es una institución consensual (SIC), prevaleciendo la voluntad de las partes dentro del principio procesal de que la composición de las partes prevalece por sobre la composición judicial;

d) La Conciliación, señala textualmente la ley, no constituye acto jurisdiccional;

e) El Art. $5^{\circ}$ de la ley define la Conciliación del siguiente modo: "Art. $5^{\circ}$.- La conciliación extrajudicial es una institución que se constituye como un mecanismo alternativo para la solución de conflictos, por el cual las partes acuden ante un Centro de Conciliación o al Juzgado de paz letrado a fin que se les asista en la búsqueda de una solución consensual al conflicto».

f) El Art. $6^{\circ}$ señala imperativamente que la Conciliación es requisito de procesabilidad necesariamente antecedente de los procesos judiciales relacionados a derechos de libre disponibilidad de las partes, sin excepción. No están comprendidos en ello los derechos de familia que no sea el derecho de alimentos, régimen de visitas y las denuncias por violencia familiar;

g) La audiencia única de la Conciliación puede tener una o más sesiones;

h) La asistencia de las partes a la audiencia de conciliación es facultativa, y la ausencia de una o de las dos partes da como lugar la culminación del proceso de Conciliación;

i) De la audiencia de Conciliación se confeccionará un acta, la misma que constituye Título de Ejecución cuando de su contenido se desprenda válidamente una obligación exigible en razón del tiempo, lugar y modo;

j) No obstante no ser un acto jurisdiccional, la ley señala que el inicio del proceso de conciliación interrumpe los plazos de prescripción y caducidad, como en el caso de la impetración por medio de una demanda;

k) El conciliador es definido como una persona capacitada y acreditada que deberá cumplir sus labores en un Centro de Conciliación, que propicia el proceso de comunicación de las partes, y que propondrá fórmulas conciliatorias sobre la base de cada caso, pero que 
no serán vinculantes, con plena libertad de acción, de acuerdo con los principios de esta ley;

1) Los Centros de conciliación serán entidades que tendrán por objeto ejercer la labor conciliatoria. Podrán serlo las personas jurídicas de derecho público o privado sin fines de lucro, que tengan entre sus finalidades el ejercicio de la función conciliadora;

m) Habrá una Junta Nacional de Conciliación que tendrá forma de persona jurídica, y servirá para coordinar sus acciones a nivel nacional, promover la eficiencia de los Centros de Conciliación y difundir la Conciliación como mecanismo pacífico y adecuado de solución de conflictos; $y$,

n) Se determina que los Jueces de paz - letrados y no letrados- serán conciliadores natos de pleno derecho en los procesos bajo su conocimiento y conforme a las reglas de esta ley. 